03,13

\title{
Эпитаксиальный рост пленок селенида кадмия на кремнии с буферным слоем карбида кремния
}

\author{
(C) В.В. Антипов ${ }^{1,2}$, С.А. Кукушкин ${ }^{1,3,4,9}$, А.В. Осипов ${ }^{1,3}$, В.П. Рубец ${ }^{2}$ \\ ${ }^{1}$ Институт проблем машиноведения РАН, \\ Санкт-Петербург, Россия \\ ${ }^{2}$ Санкт-Петербургский государственный технологический институт (технический университет), \\ Санкт-Петербург, Россия \\ ${ }^{3}$ Санкт-Петербургский национальный исследовательский университет \\ информационных технологий, механики и оптики, \\ Санкт-Петербург, Россия \\ ${ }^{4}$ Санкт-Петербургский государственный политехнический университет Петра Великого, \\ Санкт-Петербург, Россия \\ ฯ E-mail: sergey.a.kukushkin@gmail.com
}

(Поступила в Редакцию 26 сентября 2017 г.)

Методом испарения и конденсации в квазизамкнутом объеме впервые выращен эпитаксиальный кубический селенид кадмия толщиной $350 \mathrm{~nm}$ на кремнии. Установлено, что оптимальная температура подложки в данном методе составляет $590^{\circ} \mathrm{C}$, испарителя $-660^{\circ} \mathrm{C}$, время роста $-2 \mathrm{~s}$. Для того чтобы избежать стравливания кремния селеном с образованием аморфного $\mathrm{SiSe}_{2}$, на поверхности кремния предварительно был синтезирован методом замещения атомов высококачественный буферный слой карбида кремния толщиной $~ 100 \mathrm{~nm}$. Порошковая дифрактограмма и рамановский спектр однозначно соответствуют кубическому кристаллу селенида кадмия. Эллипсометрический, рамановский и электронографический анализ показали высокое структурное совершенство слоя селенида кадмия и отсутствие поликристаллической фазы.

Работа выполнена при финансовой поддержке Российского научного фонда (грант № 14-12-01102).

DOI: $10.21883 /$ FTT.2018.03.45552.275

\section{1. Введение}

Селенид кадмия $(\mathrm{CdSe})$ - типичный представитель полупроводников группы соединений $A^{2} B^{6}$. К этой группе относятся такие полупроводниковые соединения как сульфид кадмия (CdS), теллурид кадмия (CdTe), оксид цинка $(\mathrm{ZnO})$ и целый ряд других соединений. Соединения $A^{2} B^{6}$ и твердые растворы на их основе широко используются при изготовлении инфракрасных датчиков, тонкопленочных излучателей, акустических приборов различного назначения. Используются они также и в качестве элементов солнечных батарей. Являясь алмазоподобными полупроводниками, соединения типа $A^{2} B^{6}$ кристаллизуются в структуре кубического (сфалерит) или гексагонального (вюрцит) типа. Химическая связь в соединениях $A^{2} B^{6}$ является ковалентноионной и по сравнению с полупроводниками типа $A^{3} B^{5}$ в халькогенидах более сильно выражена ионная составляющая связи. Это обусловлено большими различиями в электроотрицательностях элементов, образующих соединения $A^{2} B^{6}$. С ростом средней атомной массы халькогена уменьшаются ширина запрещенной зоны и температура плавления соединений $A^{2} B^{6}$, но при этом возрастает подвижность носителей заряда. Из-за увеличения межатомных расстояний прочность химических связей падает при переходе от сульфидов к селенидам и далее - к теллуридам кадмия.
$\mathrm{CdSe}$ используется в качестве активной среды в полупроводниковых лазерах, для изготовления фоторезисторов, фотодиодов и солнечных батарей. При нарушении стехиометрии или введении в кристаллы CdSe посторонних примесей, например элементов I и VII групп периодической системы, таких как медь или хлор, CdSe приобретает фоточувствительность. Благодаря наличию этого свойства $\mathrm{CdSe}$ в свое время широко использовался для изготовления мишеней видиконов (кадмиконов), работающих в видимой области спектра. В массивных образцах $\mathrm{CdSe}$ может кристаллизоваться как в гексагональной структуре вюрцита, так и в кубической структуре сфалерита (цинковой обманки). Вюрцит представляет собой низкотемпературную фазу, которая превращается в сфалерит при температуре $700-800^{\circ} \mathrm{C}$. Тонкие пленки соединений $\mathrm{CdSe}$ в зависимости от условий осаждения могут содержать любую из этих фаз или их смесь [1].

Селенид кадмия (CdSe) является прямозонным полупроводником $A^{2} B^{6}$ (ширина зоны у кубического CdSe $1.70 \mathrm{eV}$, у гексагонального - $1.73 \mathrm{eV})$. Интерес к нему в последние годы заметно вырос благодаря различным возможным применениям $\mathrm{CdSe}$ в микроэлектронике и оптоэлектронике, в частности в светодиодах, лазерах, фотоэлектрических преобразователях, солнечных элементах, элементах памяти и т.д. С этой целью очень часто необходимо вырастить эпитаксиальные пленки $\mathrm{CdSe}$ на проводящей или полупроводниковой подложке. На сегодняшний день наибольший интерес представляют 
структуры, выращенные на кремниевой $(\mathrm{Si})$ подложке. Использование $\mathrm{Si}$ в качестве подложки позволяет интегрировать $\mathrm{CdSe}$ в современную кремниевую электронику. Подобная интеграция дает возможность сочетать практически неограниченные производственные и технологические возможности кремниевой индустрии с рядом уникальных электрофизических и оптических свойств CdSe. Но для этого необходимо выращивать эпитаксиальные высокосовершенные слои $\mathrm{CdSe}$ на $\mathrm{Si}$, что является далеко нетривиальной задачей. Действительно, как нами было показано ранее, при исследовании роста сульфида и теллурида кадмия на кремнии [2,3], соединения $A^{2} B^{6}$ в процессе синтеза пленок на $\mathrm{Si}$ при температурах выше $200^{\circ} \mathrm{C}$ могут вступать в химическое взаимодействие с подложкой $\mathrm{Si}$, что приводит к нарушению межфазной границы раздела пленка-подложка и к поликристаллическому росту пленок. Для получения эпитаксиальных пленок сульфида и теллурида кадмия $(\mathrm{CdS}$ и $\mathrm{CdTe})$ на кремнии в работах $[2,3]$ было предложено использовать буферный слой между подложкой $\mathrm{Si}$ и пленкой соединения $A^{2} B^{6}$. В качестве буферного слоя в [2,3] был использован тонкий эпитаксиальный слой карбида кремния ( $\mathrm{SiC})$. Однако при использовании в качестве буферного слоя $\mathrm{SiC}$, при получения эпитаксиальных пленок $A^{2} B^{6}$ возникают проблемы с определением параметров осаждения пленок на начальных стадиях их роста. Группой Калинкина [1] эти параметры были определены для роста пленок $\mathrm{CdS}, \mathrm{CdSe}$ и CdTe на слюде. На подложках $\mathrm{Si}$, покрытых слоем $\mathrm{SiC}$, условия синтеза этих пленок будут существенно другими. Отметим, что условия, необходимые для роста эпитаксиальных пленок каждого из соединений $\mathrm{CdS}, \mathrm{CdSe}$ и $\mathrm{CdTe}$, отличаются друг от друга, что связано с существенной разницей в адсорбции и поверхностной диффузии молекул и атомов серы, селена и теллура на поверхности $\mathrm{SiC}$. Поэтому для прогнозирования экспериментальных условий эпитаксиального роста этих соединений на $\mathrm{SiC}$ мы воспользовались теоретическими положениями, развитыми в работах [4-8]. В данной работе будут описаны экспериментальные результаты по росту $\mathrm{CdSe}$ на подложке $\mathrm{Si}$ со слоем $\mathrm{SiC}$ и определены параметры, необходимые для роста эпитаксиальных, монокристаллических слоев $\mathrm{CdSe}$ на $\mathrm{Si}$ со слоем $\mathrm{SiC}$.

\section{2. Методика эксперимента}

Эпитаксиальный слой $3 C$-SiC выращивался на $\mathrm{Si}(111)$ марки КДБ-10 методом химического замещения атомов $[9,10]$. Для этого использовалась топохимическая реакция между монокристаллической подложкой $\mathrm{Si}$ и газообразным монооксидом углерода $\mathrm{CO}$ :

$$
2 \mathrm{Si}(\text { crystal })+\mathrm{CO}(\text { gas })=\mathrm{SiC}(\text { crystal })+\mathrm{SiO}(\text { gas }) \uparrow+V_{\mathrm{Si}} \text {. }
$$

В работах [10-12] была построена термодинамическая и кинетическая модели данного топохимического превращения как фазового перехода первого рода через промежуточную фазу. Была выяснена природа самой промежуточной фазы, которая играет роль промежуточного состояния в двухстадийной топохимической реакции образования $\mathrm{SiC}$ из $\mathrm{Si}$ :

$$
\begin{aligned}
\mathrm{CO}(\text { gas })+\mathrm{Si}(\text { crystal })= & \mathrm{C}(\text { point defect in } \mathrm{Si}) \\
& +V_{\mathrm{Si}}+\mathrm{SiO}(\text { gas }),
\end{aligned}
$$

$\mathrm{Si}($ crystal $)+\mathrm{C}($ point defect in $\mathrm{Si})+V_{\mathrm{Si}}=\mathrm{SiO}($ crystal $)$,

где $V_{\mathrm{Si}}$ - кремниевая вакансия. Этим промежуточным состоянием является так называемый „предкарбидный“ кремний, т.е. кремний, насыщенный парами дефектов $\mathrm{C}+V_{\mathrm{Si}}$. Фактически это кремний, где каждый второй атом замещен на атом углерода. Предкарбидный кремний полностью готов к превращению в карбид кремния. Данный фазовый переход сопровождается образованием пустот, так как объем ячейки $\mathrm{SiC}$ в 2 раза меньше объема исходной ячейки Si. Такое превращение (3) происходит послойно (одновременно превращаются несколько слоев) со сдвигом пленки перпендикулярно поверхности подложки. Стадия (3) протекает заметно позже стадии реакции замещения (2), так как пленка $\mathrm{SiC}$ образуется достаточно однородной по толщине и без заметных пустот. В работах [9-12] связанные пары точечных дефектов $\mathrm{C}+V_{\mathrm{Si}}$ были названы дилатационными диполями по аналогии с электрическими диполями. Теория дилатационных диполей на основе функции Грина для точечного дефекта в кристалле с кубической симметрией была построена в работах $[9,10,13]$. Ключевым результатом здесь является то, что точечные дефекты C и $V_{\mathrm{Si}}$ сильно притягиваются друг к другу по направлению $\langle 111\rangle$, обеспечивая релаксацию упругой энергии промежуточного состояния. Данный результат подтвержден недавно квантово-химическими расчетами в рамках метода функционала плотности [14]. Этим объясняется низкая концентрация дислокаций несоответствия в конечном продукте реакции - пленке $\mathrm{SiC}$.

Топохимическая реакция (1) протекала в вакуумной печи при температуре $T=1250^{\circ} \mathrm{C}$ и давлении $\mathrm{CO}$ $p_{\text {CO }}=2$ Torr в течение $25 \mathrm{~min}$. При этом образовывалась эпитаксиальная пленка $3 C$ - $\mathrm{SiC}$ толщиной примерно $100 \mathrm{~nm}$. Под пленкой $\mathrm{SiC}$ в объеме $\mathrm{Si}$ обычно формируются пустоты и полости (рис. 1), вызванные образованием карбида кремния, так как объем ячейки кубического $\mathrm{SiC}$ в 2 раза меньше объема соответствующей ячейки кубического $\mathrm{Si}$ [11]. На качество $\mathrm{SiC}$ они не влияют $[15,16]$.

Затем на полученные темплейты Si с буферным слоем $\mathrm{SiC}$ методом испарения и конденсации в квазизамкнутом объеме [1] осаждались пленки CdSe. Метод испарения и конденсации в квазизамкнутом объеме был выбран потому, что он хорошо подходит для получения ориентированных пленок $A^{2} B^{6}$ в тех случаях, когда давление паров компонентов значительно отличаются [1]. 


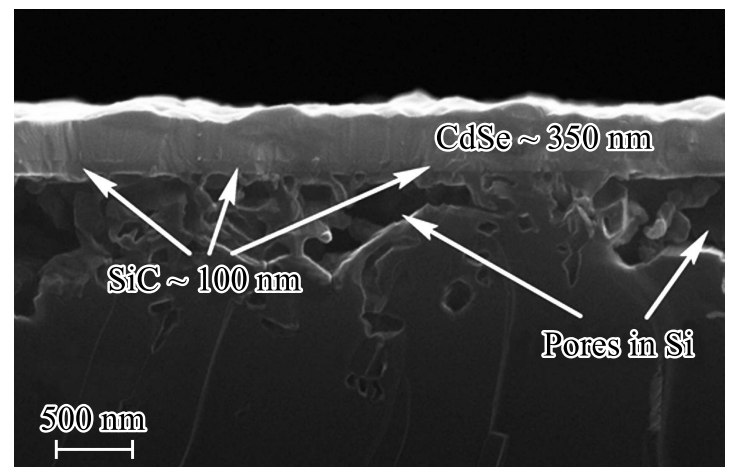

Рис. 1. Изображение среза образца $\mathrm{CdSe} / \mathrm{SiC} / \mathrm{Si}$, полученное растровым электронным микроскопом. Под слоем $\mathrm{SiC}$ видны поры и пустоты в объеме $\mathrm{Si}$.

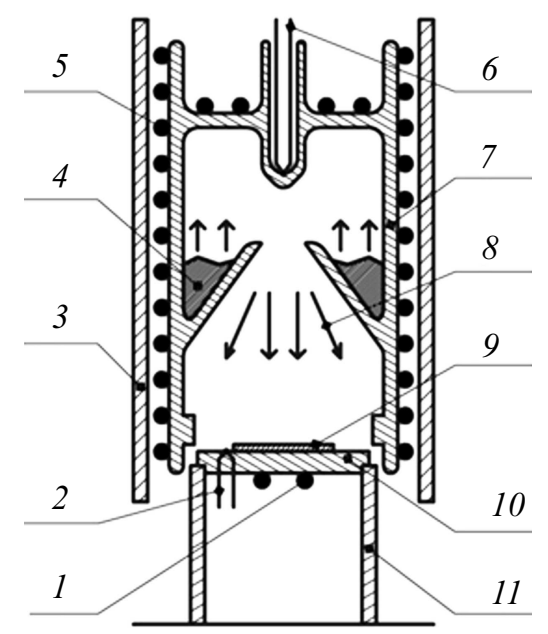

Рис. 2. Схематическое изображение схемы установки. 1 нагреватель подложки, 2 - термопара подложки, 3 - тепловой экран, 4 - порошок CdSe, 5 - нагреватель испарителя, 6 - термопара испарителя, 7 - испаритель из кварца, 8 - поток испаряемого вещества, 9 - подложка, $10-$ подложкодержатель, 11 - кварцевая труба.

На рис. 2 изображена схема установки, разработанная для роста пленок $\mathrm{CdSe}$ методом испарения и конденсации в квазизамкнутом объеме [1]. Источником селенида кадмия служил порошок $\mathrm{CdSe}$, полученный дроблением монокристаллического слитка. До выхода на заданный температурный режим испаритель находился вдали от подложки в закрытом состоянии. Затем с помощью манипулятора испаритель 7 приближали к подложке 9 (см. рис. 2) на время синтеза. Вакуум поддерживался на уровне $\sim 10^{-3} \mathrm{~Pa}$. Температура испарителя $660^{\circ} \mathrm{C}$ обеспечивала необходимую плотность падающего потока атомов. Время роста было выбрано минимально возможным, а именно $\sim 2 \mathrm{~s}$, чтобы исключить перегрев подложки от испарителя. Температура подложки $590^{\circ} \mathrm{C}$ была подобрана опытным путем для получения пленок $\mathrm{CdSe}$ с наиболее совершенной структурой.

\section{3. Результаты исследований}

Пленки $\mathrm{CdSe}$, выращенные методом испарения и конденсации в квазизамкнутом объеме на подложках $\mathrm{SiC} / \mathrm{Si}$, исследовались различными методами, в частности, рамановской спектроскопией, спектральной эллипсометрией в диапазоне $0.5-9.3 \mathrm{eV}$, дифракцией быстрых электронов, а также дифракцией рентгеновских лучей.

Основной результат анализа заключается в том, что на кремниевых подложках с буферным слоем $\mathrm{SiC}$ растет эпитаксиальный $\mathrm{CdSe}$ с кубической структурой сфалерита (на кремнии без буферного слоя образуется только поликристаллическая фаза).

На рис. 1 приведено изображение среза образца $\mathrm{CdSe} / \mathrm{SiC} / \mathrm{Si}$, полученное сканирующим электронным микроскопом. Слой $\mathrm{CdSe}$ имеет толщину около $350 \mathrm{~nm}$. Под слоем карбида кремния толщиной $\sim 100 \mathrm{~nm}$ отчетливо видны поры и пустоты в объеме подложки кремния, которые образовались в результате топохимической реакции (1). Их образование напрямую связано с релаксацией упругих напряжений на границе раздела $\mathrm{SiC} / \mathrm{Si}$ и отсутствием на ней дислокаций несоответствия решеток [15], на качество $\mathrm{SiC}$ они не влияют $[15,16]$.

На рис. 3 приведен рамановский спектр образца $\mathrm{CdSe} / \mathrm{SiC} / \mathrm{Si}$. Несмотря на относительно малую толщину CdSe $(\sim 350 \mathrm{~nm})$ отчетливо видны как пик $\sim 205 \mathrm{~cm}^{-1}$, отвечающий оптической фононной моде $\mathrm{CdSe}(\mathrm{LO})$, так и пик $\sim 411 \mathrm{~cm}^{-1}$, отвечающий оптической фононной моде $\mathrm{CdSe}$ второго порядка (2LO). Для того чтобы определить какой политип $\mathrm{CdSe}$ вырос, кубический или гексагональный, а также сравнить измеренный рамановский спектр CdSe c теоретическим, в настоящей работе методами квантовой химии были вычислены рамановские спектры как кубического, так и гексагонального CdSe. Использовался метод функционала плотности в приближении градиентного функционала

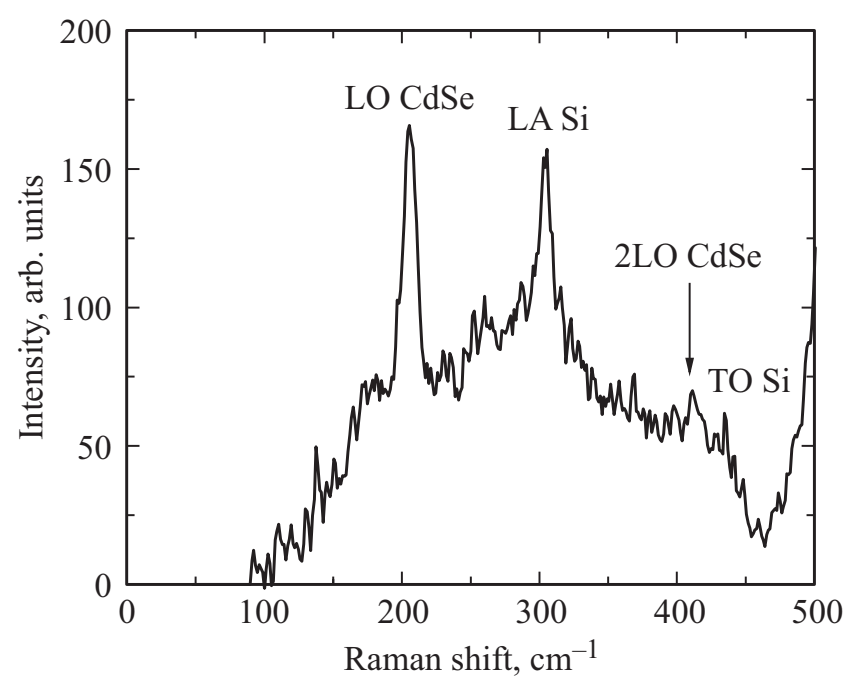

Рис. 3. Рамановский спектр образца $\mathrm{CdSe} / \mathrm{SiC} / \mathrm{Si}$. Пики $\mathrm{CdS}$ отвечают оптическим фононным модам первого и второго порядка (1LO) и (2LO). 


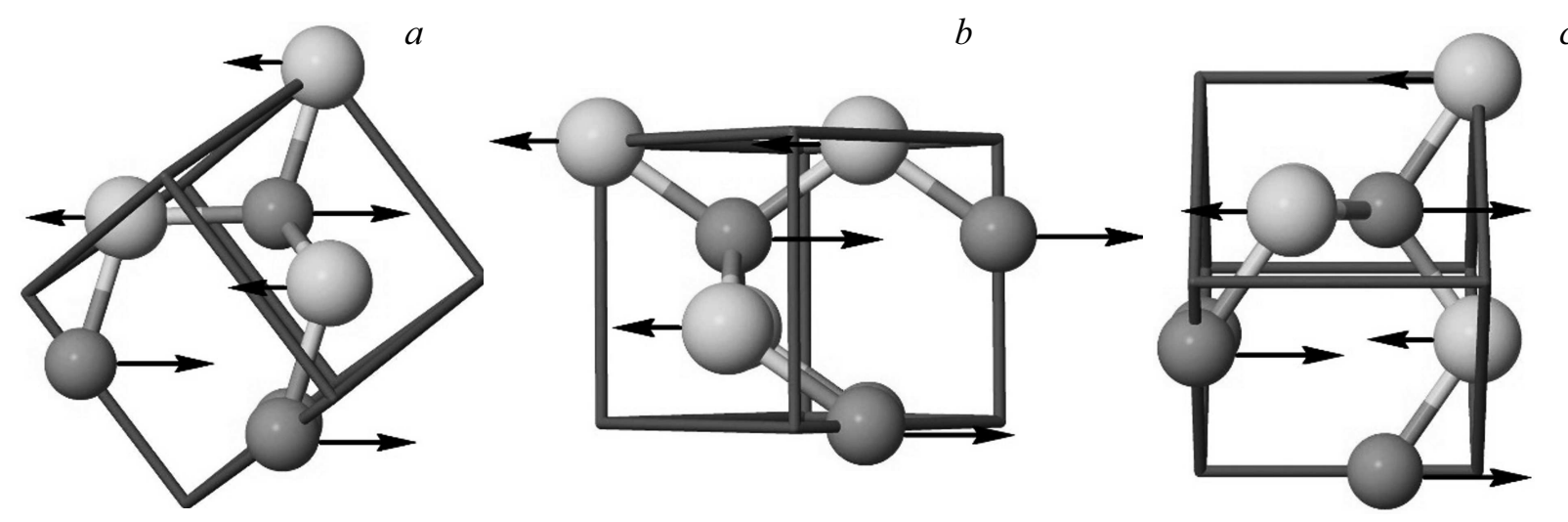

Рис. 4. Три моды колебаний, отвечающие линии $1 \mathrm{LO}$ рамановского спектра кубического CdSe $\mathrm{c}$ частотой $205 \mathrm{~cm}^{-1}($ рис. 3$)$. Большие светлые шарики соответствуют атомам $\mathrm{Cd}$, маленькие темные - атомам Se. Стрелки показывают направление колебаний атомов.

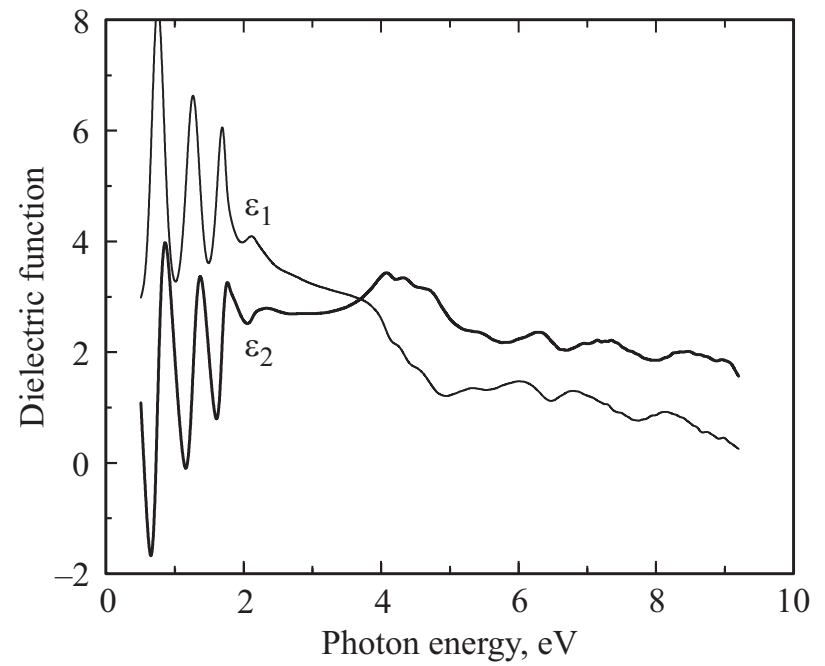

Рис. 5. Зависимость вещественной $\varepsilon_{1}$ и мнимой $\varepsilon_{2}$ частей псевдодиэлектрической проницаемости образца $\mathrm{CdSe} / \mathrm{SiC} / \mathrm{Si}$ от энергии фотонов, измеренная на эллипсометре VUV-Vase J.A. Woollam.

PW91 [17]. Минимум функционала находился в базисе плоских волн с использованием нормосохраняющих псевдопотенциалов. Энергия обрезания плоских волн $500 \mathrm{eV}$ выбиралась на основе предварительного анализа сходимости результатов. Собственные частоты колебаний и их рамановские интенсивности вычислялись с использованием кода Quantum Espresso [18]. В обоих случаях рассматривалась только примитивная ячейка с периодическими граничными условиями по всем трем измерениям. Расчеты показали, что рамановский спектр кубического CdSe состоит всего из одной линии первого порядка $\sim 201 \mathrm{~cm}^{-1}$ (линии более высоких порядков не вычислялись). В силу симметрии кубического кристалла $\mathrm{CdSe}$ данной частоте отвечают сразу три моды продольных оптических колебаний, изображенные на рис. 4. Рамановский спектр вюрцитного $\mathrm{CdSe}$, полученный в этом же приближении, состоит из двух линий высокой интенсивности 61 и $181 \mathrm{~cm}^{-1}$ и одной линии слабой интенсивности $191 \mathrm{~cm}^{-1}$. Экспериментальный рамановский спектр показывает только одну линию первого порядка $205 \mathrm{~cm}^{-1}$, что гораздо ближе к кубическому CdSe.

На рис. 5 представлена зависимость диэлектрической проницаемости образца $\mathrm{CdSe} / \mathrm{SiC} / \mathrm{Si}$ от энергии фотонов в интервале $0.5-9.3 \mathrm{eV}$, измеренной на эллипсометре VUVase J.A. Woollam $\left(\varepsilon_{1}-\right.$ вещественная часть диэлектрической проницаемости, $\varepsilon_{2}-$ ее мнимая часть [19]). Измеренная зависимость может быть описана теоретически, используя простейшую однослойную эллипсометрическую модель $[19,20]$. На подложке $\mathrm{SiC} / \mathrm{Si}$ с заранее измеренными оптическими константами лежит слой $\mathrm{CdSe}$, оптические константы которого неизвестны и описываются сплайнами [19]. Между подложкой и $\mathrm{CdSe}$ лежит промежуточный слой $(50 \% \mathrm{CdSe}, 50 \% \mathrm{SiC})$,

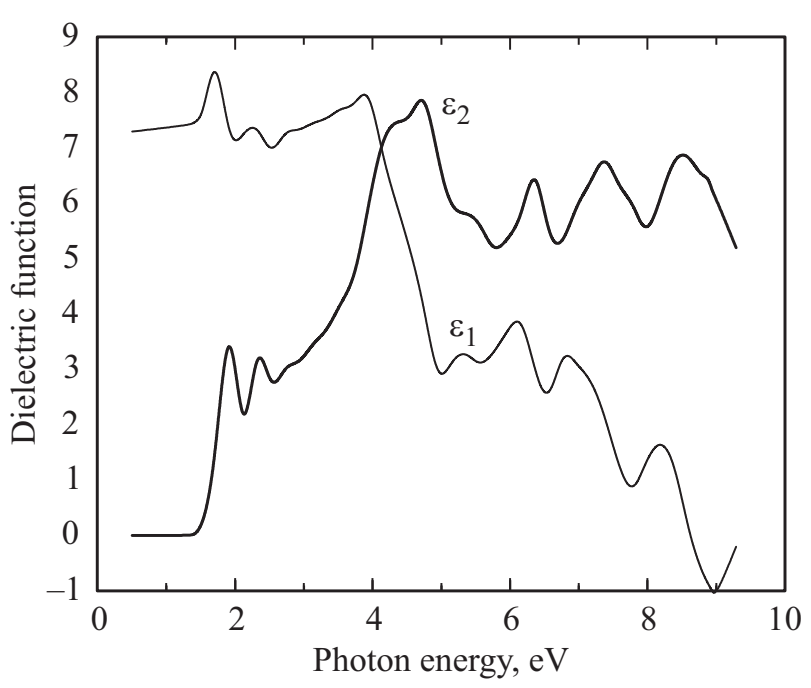

Рис. 6. Оптические константы CdSe, вычисленные из экспериментальных данных рис. 5 с помощью аппроксимации сплайнами. 


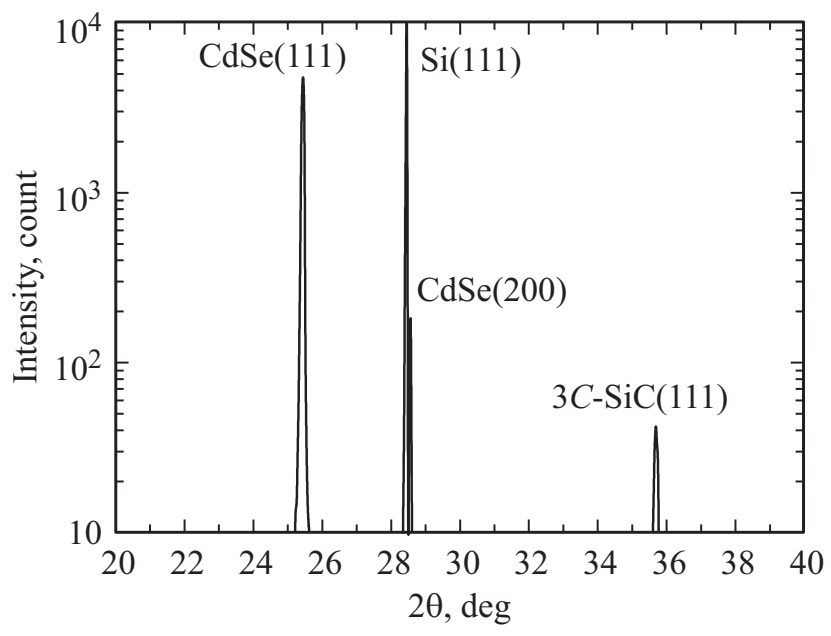

Рис. 7. Порошковая дифрактограмма образца $\mathrm{CdSe} / \mathrm{SiC} / \mathrm{Si}$. Оба зарегистрированных пика $\mathrm{CdSe}$ отвечают кубической структуре кристалла CdSe.

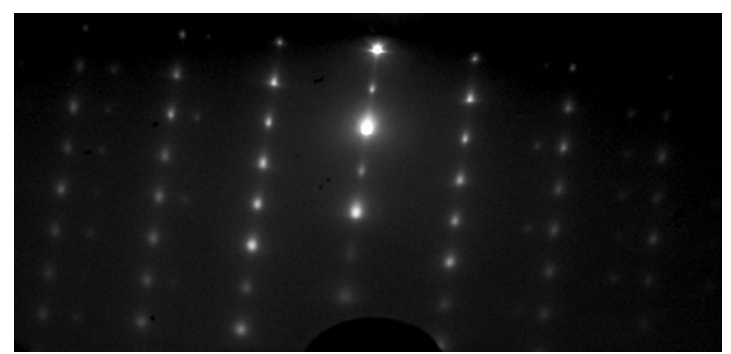

Рис. 8. Электронограмма образца $\mathrm{CdSe} / \mathrm{SiC} / \mathrm{Si}$, полученная электронографом ЭМР-100 при энергии электронов $50 \mathrm{keV}$. Поликристаллическая фаза отсутствует.

сверху CdSe лежит слой, описывающий шероховатость (50\% $\mathrm{CdSe}, 50 \%$ вакуум). Толщины промежуточного слоя и слоя шероховатости не превышают $10 \mathrm{~nm}$, поэтому традиционно они не считаются полноправными слоями. Толщина слоя $\mathrm{CdSe}$ и параметры сплайна, описывающего его оптические константы, подбираются из наилучшего совпадения теоретических и экспериментальных результатов. Таким образом из эллипсометрических спектров вычисляются толщина слоя $\mathrm{CdSe}$, которая оказалась равной $350 \pm 10 \mathrm{~nm}$, и его диэлектрическая проницаемость (рис. 6). Отчетливо видна прямая запрещенная зона $\sim 1.7 \mathrm{eV}$.

Дифрактограмма образца $\mathrm{CdSe} / \mathrm{SiC} / \mathrm{Si}$, зарегистрированная порошковым дифрактометром, показана на рис. 7. В интервале от 20 до $40^{\circ}$ помимо пиков $\mathrm{Si}$ и $3 C$ - $\mathrm{SiC}$ имеются лишь два пика: $25.4^{\circ}$ и $28.6^{\circ}$. Оба пика отвечают кубическому CdSe. Ни один из четырех пиков в данном диапазоне, отвечающих вюрцитному $\mathrm{CdSe}$, а именно $23.4,24.8,26.5,38.4^{\circ}$, на данной дифрактограмме не зарегистрирован, что позволяет однозначно отождествить данный образец как кубический $\mathrm{CdSe}$.
На рис. 8 показана картина дифракции быстрых электронов для образца $\mathrm{CdSe} / \mathrm{SiC} / \mathrm{Si}$, полученная на электронографе ЭМР-100 при энергии электронов $50 \mathrm{keV}$. Ясно видна эпитаксиальная структура CdSe c некоторым количеством двойников, поликристаллическая фаза отсутствует. Аналогичная дифракционная картина для образца $\mathrm{CdSe}$, выращенного в тех же условиях непосредственно на подложке $\mathrm{Si}$, дает лишь поликристаллическую структуру без следов эпитаксии, что объясняется прежде всего реакцией кремния с селеном с образованием $\mathrm{SiSe}_{2}$. Образующийся аморфный $\mathrm{SiSe}_{2}$ мешает когерентному сопряжению решеток $\mathrm{CdSe}$ и $\mathrm{Si}$.

\section{4. Заключение}

Таким образом, в настоящей работе на примере CdSe доказано, что использование $\mathrm{SiC}$ в качестве буферного слоя для роста полупроводников $A^{2} B^{6}$ на $\mathrm{Si}$ предохраняет кремний от соединения его с элементами VI группы, что обеспечивает стехиометрический эпитаксиальный рост пленки $A^{2} B^{6}$. Буферный слой $\mathrm{SiC}$ на $\mathrm{Si}$ толщиной порядка $100 \mathrm{~nm}$ предлагается получать методом замещения атомов [9-12], что обеспечивает совершенную структуру $\mathrm{SiC}$ при низкой концентрации дислокаций несоответствия решеток. В данной работе таким методом был впервые получен эпитаксиальный $\mathrm{CdSe}$ c кубической структурой на $\mathrm{Si}$. Кубическая структура установлена с помощью рентгеноструктурного анализа и анализа рамановского спектра. Эллипсометрические спектры показали прямую запрещенную зону эпитаксиального $\mathrm{CdS}$, равную $1.7 \mathrm{eV}$. Рамановский и электронографический анализ показали высокое структурное совершенство слоя $\mathrm{CdSe}$ и отсутствие поликристаллической фазы.

Авторы признательны И.П. Калинкину за обсуждения процесса роста пленок CdSe.

\section{Список литературы}

[1] И.П. Калинкин, В.Б. Алесковский, А.В. Симашкевич. Эпитаксиальные пленки соединений $A^{\mathrm{II}} B^{\mathrm{VI}}$. Изд-во ЛГУ, Л. (1978). $311 \mathrm{c}$.

[2] В.В. Антипов С.А. Кукушкин, А.В. Осипов. ФТТ 58, 612 (2016).

[3] В.В. Антипов С.А. Кукушкин, А.В. Осипов. ФТТ 59, 385 (2017).

[4] S.A. Kukushkin, A.V. Osipov. In: Encyclopedia of nanoscience and nanotechnology. V. 8 / Ed. H.S. Nalwa. American Scientific Publ., Valencia (2004). P. 113.

[5] S.A. Kukushkin, A.V. Osipov. Phys. Rev. B 65, 174101 (2002).

[6] S.A. Kukushkin, A.V. Osipov. Surf. Sci. 329, 135 (1995).

[7] S.A. Kukushkin, A.V. Osipov. Thin Solid Films. 227, 119 (1993).

[8] V.G. Dubrovskii. Nucleation theory and growth of nanostructures. Springer, Berlin (2014). $601 \mathrm{p}$.

[9] S.A. Kukushkin, A.V. Osipov. J. Appl. Phys. 113, 024909 (2013). 
[10] S.A. Kukushkin, A.V. Osipov. J. Phys. D 47, 313001 (2014).

[11] С.А. Кукушкин, А.В. Осипов, Н.А. Феоктистов. ФТТ 56, 1457 (2014).

[12] С.А. Кукушкин, А.В. Осипов. ФТТ 56, 761 (2014).

[13] С.А. Кукушкин, А.В. Осипов, Р.С. Телятник. ФТТ 58, 941 (2016).

[14] С.А. Кукушкин, А.В. Осипов. ФТТ 59, 1214 (2017).

[15] Л.М. Сорокин, Н.В. Веселов, М.П. Щеглов, А.Е. Калмыков, А.А. Ситникова, Н.А. Феоктистов, А.В. Осипов, С.А. Кукушкин. Письма в ЖТФ 34, 88 (2008).

[16] T.S. Perova, J. Wasyluk, S.A. Kukushkin, A.V. Osipov, N.A. Feoktistov, S.A. Grudinkin. Nanoscale Res. Lett. 5, 1507 (2010).

[17] J.P. Perdew, Y. Wang. Phys. Rev. B 45, 13244 (1992).

[18] P. Giannozzi, S. Baroni, N. Bonini et al. J. Phys.: Condens Matter. 21, 395502 (2009).

[19] H.G. Tompkins, J.N. Hilfiker. Spectroscopic ellipsometry. Practical application to thin film characterization. Momentum Press, N. Y. (2016). 159 p.

[20] С.А. Кукушкин, А.В. Осипов. ФТП 47, 1575 (2013). 